\title{
GESTÃO À SUSTENTABILIDADE: REFLEXÕES A PARTIR DE DIMENSÕES DE ANÁLISE E OBSERVAÇÃO COM GESTORES DE ORGANIZAÇÕES DA REGIÃO DO ALTO VALE DO ITAJAÍ EM SANTA CATARINA
}

\author{
Rubens Staloch ${ }^{1}$ \\ 'rubens.staloch@udesc.br
}

\section{Resumo}

Exercer gestão empresarial está relacionado ao conjunto de ferramentas e decisões visando maximizar resultados, bem como, atender necessidades humanas. Atualmente, é preciso convergir gestão e produção com os preceitos do desenvolvimento sustentável. Neste sentido, a pesquisa apresentada tem como problemática responder a questão: os gestores de organizações empresariais da região do Alto Vale do Itajaí em Santa Catarina compreendem as diferentes dimensões de sustentabilidade? O presente texto perfaz inicialmente uma discussão teórica, a partir de procedimento de pesquisa bibliográfica exploratória, acerca de teorias da administração e do desenvolvimento sustentável. Ainda, se utilizou da técnica de entrevista para coleta dos dados e, para reflexão sobre os mesmos, se usou da análise de conteúdo. Como resultado se verificou que: i) entre os gestores entrevistados, ainda é recorrente a relação entre sustentabilidade e "ecologia", unicamente; ii) o discurso é baseado em generalizações. Por fim, frisa-se que $\mathrm{o}$ ato de praticar e implementar ações integradas que contribuam ao desenvolvimento sustentável é o maior valor para o cliente e para a sociedade.

Palavras-chave: Gestão. Sustentabilidade. Organizações. Alto Vale do Itajaí.

\section{MANAGEMENT TO SUSTAINABILITY: REFLECTIONS FROM DIMENSIONS OF ANALYSIS AND OBSERVATION WITH MANAGERS OF ORGANIZATIONS OF THE ALTO VALE DO ITAJAÍ REGION IN SANTA CATARINA}

\begin{abstract}
Exercising business management is related to the set of tools and decisions aimed at maximizing results as well as meeting human needs. Currently, it is necessary to converge management and production (of goods and services and profits) with the precepts of sustainable development (different dimensions). In this sense, the research presented has the problem of answering the following question: the managers of business organizations in the Alto Vale do Itajai (Santa Catarina) region understand the different dimensions of sustainability? The present text initially makes a theoretical discussion, based on a procedure of exploratory bibliographical research, about theories of administration and sustainable development. In addition, the interview technique was used to collect the data and, in order to reflect on them, the content analysis was used. As a result, it was verified that: i) among the interviewed managers, the relationship between sustainability and "ecology" is still recurrent (only); ii) discourse based on generalizations. Finally, it is emphasized that practicing and implementing (integrated) actions that contribute to sustainable development is the greatest value for the client and for society.
\end{abstract}

Keywords: Management. Sustainability. Companies. Alto Vale do Itajaí.

R. Eletr. do Alto Vale do Itajaí - REAVI, v. 7, n. 11, p. 01-09, dez., 2018 ISSN: 2316-4190, DOI: $10.5965 / 2316419007112018103$ 


\section{Introdução}

O resultado atual da sociedade é dado pela interação dos geossistemas (SOTCHAVA, 1978) e o processo de formação socioespacial (SANTOS, 1977; 1978). Antropologicamente, uma sociedade é o resultado de indivíduos atuando em conjunto (ELIAS, 1994). Neste sentido, pensar em uma sociedade sustentável, requer pensar e agir de forma conjunta: cidadãos, empresas, instituições etc., permitindo que as futuras gerações possam usufruir e viver qualitativamente no planeta. Observando o contexto empresarial, é imprescindível analisar o processo de gestão desempenhado, bem como, o que os gestores entendem e observam sobre sustentabilidade.

O conceito de desenvolvimento sustentável é enfatizado a partir da década de 1980, no entanto, a expressão foi disseminada em 1972 com a Conferência das Nações Unidas, ocorrida em Estocolmo. Duas questões centrais estavam sendo debatidas na Conferência, a proteção ambiental e a reversão do crescimento demográfico. A partir destas se destacaram três aspectos: 1) a necessidade de compromisso simultâneo de preservação da natureza e do uso racional de recursos; 2) a diversidade de posições em analisar as relações entre desenvolvimento e meio ambiente; e 3) a responsabilidade atribuída à dinâmica demográfica como fator responsável das desigualdades de distribuição do crescimento econômico e pressão sobre os recursos naturais (COSTA, 2008).

No Brasil, o processo de discussão sobre desenvolvimento sustentável se iniciou de forma mais afinca após a década de 1990, sobretudo, enfatizando a dimensão ambiental, fato que se observa pela aprovação da Política Nacional de Educação Ambiental no final da década (Lei n. 9.795/1999). Porém, ao se tratar de sustentabilidade não se está falando apenas de "ecologia", mas sim, de um conjunto de dimensões, conforme descreveu Sachs (1993): ambiental, econômica, social, cultural e espacial.

Considerando que o processo de gestão empresarial está relacionado ao conjunto de ferramentas e decisões visando maximizar resultados (DAVENPORT, 1994), a partir de movimentos de coordenação (MINTZBERG et al., 2000), atualmente, é preciso convergir gestão e produção de bens e serviços e lucros, com os preceitos do desenvolvimento sustentável em diferentes dimensões (Sachs 1993). Assim se questiona, os gestores de organizações empresariais da região do Alto Vale do Itajaí em Santa Catarina compreendem as diferentes dimensões de sustentabilidade?

O texto se inicia com uma breve explanação sobre o processo de gestão empresarial a partir das teorias da administração científica e uma discussão sobre o desenvolvimento sustentável sob diferentes dimensões. Em seguida foram relatados os procedimentos metodológicos para a coleta e análise dos dados e por fim, se realizou a análise dos dados coletados e se expôs algumas considerações finais.

\section{Fundamentação Teórica}

\subsection{Processos de gestão do passado ao presente: desenvolvimento sustentável e dimensões de análise}

Pensar em uma estrutura organizacional requer entender os processos de gestão. Para Davenport (1994), um processo é um conjunto de atividades estruturadas e medidas, destinadas a resultar num produto específico para um determinado cliente ou mercado. Segundo Araújo (2009, p. 26), o conceito de processo pode ser entendido quanto sua existência, pois, "é a introdução de insumos (entradas ou inputs) num ambiente, formado por procedimentos, normas

R. Eletr. do Alto Vale do Itajaí - REAVI, v. 7, n. 11, p. 01-09, dez., 2018 ISSN: 2316-4190, DOI: $10.5965 / 2316419007112018103$ 
e regras que, ao processarem os insumos, transformaram-nos em resultados que serão enviados (saídas ou outputs) aos clientes do processo".

Desta forma, é possível sintetizar de que um processo é um conjunto de atividades interrelacionadas de forma lógica, que envolve um conjunto completo de fatores (fatores de produção) que por sua vez, resultam em produtos (bens ou serviços). Neste contexto, cabe mencionar os estudos da "Economia", que por sua vez, é uma Ciência Social que se preocupa em estudar a alocação eficiente dos fatores de produção (escassos) a fim de atender as necessidades humanas - das famílias (ilimitadas) (VASCOCELLOS, 2006). Neste escopo de análise, uma empresa ocupa (ou deveria ocupar), por meio de seus processos, o papel de atender as necessidades humanas. (Figura 1)

Figura 1 - fluxo circular da economia e a representação de um processo produtivo.

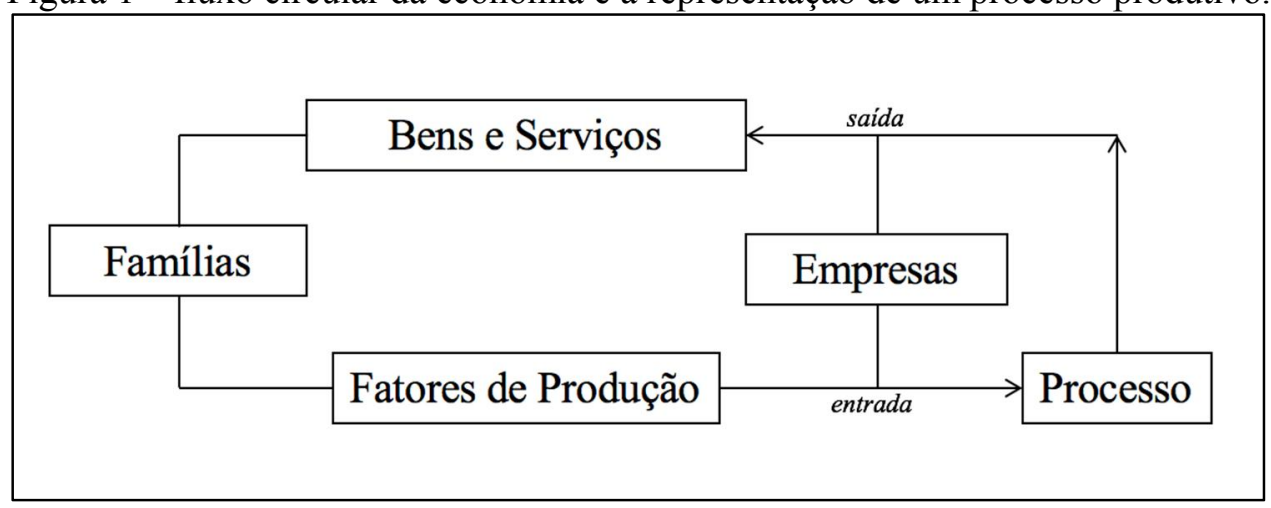

Fonte: elaboração do autor com base em (VASCONCELLOS, 2006).

Porém, o modo como se desenvolveram as relações (capitalistas) ao longo da história nos foi revelado por Marx (1989), o jogo de poder e a dominação de classes, onde os empresários europeus - pós Revolução Burguesa - (egoístas, frios e calculistas) se utilizavam de estratégias (processo de acumulação primitiva) para obterem a "mais-valia". Se evidencia assim, um processo produtivo - originário da Revolução Burguesa e da Revolução Industrial caracterizando o chamado período técnico-científico (SANTOS, 1994) - que possuía como base não mais apenas atender as necessidades humanas, mas sim, satisfazer as classes dominantes, gerando cada vez mais lucros.

Este processo somente é "consolidado" devido os processos de gestão instalados e que, por sua vez, perfazem a chamada cultura organizacional. Esta, ocupa um lugar de destaque no âmbito das organizações, sendo ela formada por pressupostos, crenças e valores compartilhados pelos membros de uma organização, sendo derivada de um ambiente social específico (MATIAS-PEREIRA, 2008). Cada organização tem uma cultura organizacional específica, apoiada, transmitida e transformada através do processo de interação social dos inúmeros e diferentes atores que nela atuam (MATIAS-PEREIRA, 2008, p. 17).

Sob a ótica histórica os processos de gestão (e administração) dos negócios, é possível perceber que para se obter sucesso é indispensável a informação, sendo que no passado, um administrador passava grande parte do tempo em busca de informações sobre o que estava acontecendo ao seu redor. Na era atual do período técnico-científico-informacional (SANTOS, 1994), não basta apenas buscar informações, mas sim, é preciso escolher e selecionar cuidadosamente as informações. Se pode, ainda, dizer que as classes dominantes eram aquelas que detinham de informações, enquanto as classes dominadas, não. Surgiu assim a teoria da "alienação do processo produtivo" (MARX, 1989), onde o proletário detinha das informações sobre todo o processo e o trabalhador já não tinha mais contato com todo o processo produtivo, ficando assim, "alienado". 
A partir desta ótica, diversas teorias da administração são evidenciadas, cada qual, tentando explicar relações no (para o) contexto organizacional. Uma das primeiras é, justamente, aquela que descreve um modelo produtivo mecanicista (Taylor - 1890 a 1925) e segmentado com foco na produção em série e subordinação funcional. A segunda, (Fayol 1890 a 1925) descreve um modelo normativista com centralização, unidade de comando e controle, normas e divisão do trabalho. A terceira, (Behaviorista - 1927 a 1940), descreve as relações humanas e o comportamento humano, onde pessoas possuem qualidades que precisam ser exploradas (visando maximizar a produção); os sentimentos humanos interferem na eficiência do trabalho (RIBEIRO, 2005).

A quarta teoria no escopo da administração diz respeito a "teoria da burocracia" e estruturalista (Weber - a partir de 1940). Weber (1982), define a burocracia como uma técnica auxiliar administrativa capaz de conduzir uma organização, onde há uma hierarquia a ser seguida. Dessa forma, a burocracia, quando analisada isoladamente perde totalmente seu sentido, pois é preciso considerar a realidade em que a organização se encontra para adaptar-se o melhor modelo de gestão (WEBER, 1982). O autor ainda coloca que a burocracia é um meio para exercer poder. É uma teoria que visa a administração impessoal e que ainda nos dias atuais é colocada em prática. Neste sentido, e perfazendo uma crítica, Morin (2013, p. 162) coloca que uma organização burocratizada tende a desumanizar os serviços, pois, "a administração burocratizada reage com excesso de rigidez e atraso aos problemas urgentes e aos desafios imediatos". E mais, a burocracia "(...) pode ser considerada uma patologia administrativa em que o excesso de centralização, o excesso de hierarquia, o excesso de formalização dos procedimentos eliminam qualquer iniciativa, qualquer sentido de responsabilidade daqueles que não podem senão obedecer, enquanto excesso de especialização isola qualquer agente e seu compartimento e seu comportamento sem estimulá-lo a usar a inteligência" (MORIN, 2013, p. 160).

A partir dos anos de 1950 (até 1970/80), surgem no escopo da administração científica, teorias baseadas em escolas dos "sistemas", "administração por objetivos", "desenvolvimento organizacional" e "contingencial", que por sua vez, passam a encarar as organizações como sistemas (integrados), inclusive, analisando os ambientes interno e externo para a tomada de decisão, entendendo a relação entre estes. Muitas das decisões são baseadas no contingenciamento, ou seja, a partir do contexto interno e externo que emergem - por exemplo, a Tecnologia da Informação e Comunicação (TIC) (RIBEIRO, 2005). Após os anos de 1980 surgem discussões acerca do processo de qualidade e melhoria contínua nos processos (gestão da qualidade - por ex. Série de ISO 9000), sendo necessária a correlação (teórica e prática) da gestão com as discussões acerca do desenvolvimento sustentável - o foco central deste trabalho.

A perspectiva de gestão de um negócio está centrada na coordenação, que por sua vez, na visão de Mintzberg (1995a; 1995b) e Mintzberg et al. (2000) requer: 1) ajustamento mútuo; 2) supervisão direta; 3) padronização das habilidades; 4) padronização dos processos; e 5) controle e comunicação. Desta forma, a gestão deve se preocupar com a racionalização das atividades organizacionais por meio da ótica de processos de negócio e visualização da organização como o conjunto de seus processos integrados que geram valor (es) para o cliente. Atualmente se fala em "gestão corporativa" ou "gestão colaborativa" ou ainda "governança corporativa", em que todos nos incitam pensar em valores amparados na integração (e participação). Estes valores precisam estar engajados com um processo (talvez utópico ainda) de desenvolvimento sustentável.

O considerado crescimento econômico não significou melhora nos indicadores sociais, principalmente nos países "periféricos". E mais, tais processos (inclusive com o auxílio da administração científica) promoveram ainda, profundos impactos ambientais que afetam direta e indiretamente todo o globo (DALY, 1999), pois, se vive na chamada "sociedade de risco" (BECK,1992). De acordo com Sen (2000), o desenvolvimento não pode se limitar ao

R. Eletr. do Alto Vale do Itajaí - REAVI, v. 7, n. 11, p. 01-09, dez., 2018 ISSN: 2316-4190, DOI: $10.5965 / 2316419007112018103$ 
crescimento dos lucros e do consumo, é preciso vislumbrar o desenvolvimento de todas as potencialidades humanas. Assim sendo, é necessário entender um pouco mais reflexivamente como se chegou ao atual estágio de discussão sobre o desenvolvimento sustentável, para que após, realizar uma análise conjunta acerca de gestão organizacional / empresarial (nos dias atuais) e sustentabilidade.

Para Bursztyn e Bursztyn (2012) existem quatro utopias que descrevem o processo de desenvolvimento sob a perspectiva histórica, analisando as dimensões do trabalho (L), recursos naturais $(\mathrm{N})$ e capital $(\mathrm{K})$. 1) industrialismo: desenvolvimento como crescimento econômico, em que nos primórdios o capital prevaleceu sobre as demais dimensões da base produtiva; 2) social-democrata: desenvolvimento social (Welfare), em que o Estado deveria atuar na redução dos riscos e incertezas, tanto sociais, quanto econômicas, conciliando as dimensões do capital (K) e do trabalho (L); 3) neoliberal: as estruturas estatais passam por um enxugamento e a dimensão ambiental das políticas públicas se enraíza no tecido institucional do Estado, coincidindo com a ascensão das preocupações ambientais proteção do meio ambiente - "O Estado relega a um segundo plano a dimensão L, mas valoriza $\mathrm{N}$ e, por se retrair como agente produtivo direto e como regulamentador, também propulsiona K" (BURSZTYN e BURSZTYN, 2012, p. 39); 4) desenvolvimento sustentável: utopia pós-industrial, em que:

A utopia industrial deixa de ser o grande atrativo das sociedades afluentes, que demandam cada vez mais qualidade de vida e ambiente saudável. O equilíbrio na hierarquia de relevância das três esferas do processo produtivo (K, L e N) se impõe como uma máxima e fundamenta o novo projeto de utopia: a sustentabilidade (BURSZTYN; BURSZTYN, 2012, p. 41).

A generalização do discurso acerca do desenvolvimento sustentável ocorre em 1987 a partir do Relatório da Comissão Mundial sobre o Meio Ambiente e Desenvolvimento (CMMDA), conhecido como Relatório Brundtland, que define oficialmente o conceito de desenvolvimento sustentável como aquele que atende às necessidades das gerações presentes sem comprometer a possibilidade das gerações futuras atenderem a suas próprias necessidades. Porém, o conceito de desenvolvimento sustentável só foi firmado na Conferência "Rio 92", onde os representantes dos 170 países presentes consolidaram o conceito como diretriz para a mudança de rumos no desenvolvimento global, a chamada Agenda 21 (BARBOSA, 2008).

O desenvolvimento sustentável é um processo que busca uma constante melhoria qualitativa no modo de vida. É evidente que a economia não poderá crescer indefinidamente já que a base física (natureza) é um fator restritivo em que não se pode explorar os recursos naturais acima de sua capacidade de regeneração nem emitir resíduos acima de sua capacidade de assimilação (resiliência) (DALY, 1991). Assim, o conceito de sustentabilidade pode ser compreendido, não como um conceito, mas sim, por meio da ação, da "continuação através do tempo" (FOLADORI e TOMMASINO, 2010).

Uma das questões centrais para o agravamento da insustentabilidade planetária foi tratada durante a "Rio-92", a densidade demográfica. De acordo com os pensamentos neomalthusianos, os grandes problemas ambientais, e, também sociais são decorrentes do crescente populacional (MARTINE, 1993, p. 9), residindo assim, uma questão: como conciliar desenvolvimento com preservação? Para Martine (1993) é necessário eliminar o pensamento de que o crescimento populacional é o único responsável pelos problemas no meio ambiente. Se faz necessário a análise de um conjunto complexo de fatores: a industrialização, o consumismo, os modelos de gestão, as más práticas cotidianas etc.

Enquanto a sociedade segue um modelo consumista, egoísta e egocêntrico, continuase com milhões de pessoas passando fome, milhares de espécies de animais e plantas sendo extintas, bilhões de pessoas sendo insustentáveis e infelizes. Há uma ironia em que "depois de

R. Eletr. do Alto Vale do Itajaí - REAVI, v. 7, n. 11, p. 01-09, dez., 2018 ISSN: 2316-4190, DOI: $10.5965 / 2316419007112018103$ 
quinhentos anos, o sonho do desenvolvimento provocou o subdesenvolvimento da maioria dos países do mundo" (BOFF, 2000, p. 68). O planeta está em crise, sendo ela, "uma descontinuidade e uma perturbação dentro da normalidade da vida provocada pelo esgotamento da possibilidade de crescimento de um arranjo existencial" (BOFF, 2002, p. 25). De que forma então se podem minimizar as consequências desta crise? Quando aceita, a crise tende a ser o momento ideal para a busca de alternativas de superação, busca de soluções, para moldar um futuro melhor (BOFF, 2002). Para que a sustentabilidade seja de fato "praticada" é necessário um constante monitoramento e avaliação ao desenvolvimento sustentável, conforme explicitado na Agenda 21 (AGENDA 21, 1999).

Importante também, observar os Objetivos do Desenvolvimento Sustentável (ODS) estipulados pela Organização das Nações Unidas (ONU). No documento "transformando nosso mundo: a agenda 2030 para o desenvolvimento sustentável" são estipulados 17 objetivos a serem alcançados pelas nações até 2030, sobretudo, objetivos vinculados às dimensões sociais, ambientais e econômicas. Os Objetivos de Desenvolvimento Sustentável 2015-2030 são: 1) Erradicação da pobreza; 2) Fome zero e agricultura sustentável; 3) Saúde e bem-estar; 4) Educação de qualidade; 5) Igualdade de gênero; 6) Água potável e saneamento; 7) Energia limpa e acessível; 8) Trabalho decente e crescimento econômico; 9) Indústria, inovação e infraestrutura; 10) Redução das desigualdades; 11) Cidades e comunidades sustentáveis; 12) Consumo e produção responsáveis; 13) Ação contra a mudança global do clima; 14) Vida na água; 15) Vida terrestre; 16) Paz, justiça e instituições eficazes; 17) Parcerias e meios de implementação. (ONU, 2018). Diversas metas estipuladas dos ODS correlacionam-se com as práticas (e necessidade de mudanças) de gestão. Ainda, cabe destaque aos dados apresentados pelo Relatório Luz (2018) de que muitos dos ODS não serão alcançados pelo Brasil.

Aproximando um pouco mais a reflexão com os processos de gestão, o que se espera com as discussões de desenvolvimento sustentável é a "gestão dos recursos planetários de forma que a qualidade e abundância entejam asseguradas para as gerações futuras no longo prazo" (THOMAS e CALLAN, 2012, p. 24), a partir de uma mudança no fluxo circular da renda e dos processos produtivos, que além de levar em consideração o padrão já conhecido na relação entre famílias, empresas, que também apresente a relação com a natureza economia ambiental, sendo que, com a aprovação da Política Nacional de Resíduos Sólidos (Lei n. 12.305/2010), o Brasil possui base legal para a implementação deste modelo de economia ambiental, inclusive, estimulando e obrigando em alguns casos, a logística reversa. (Figura 2) 
Figura 2 - economia ambiental.

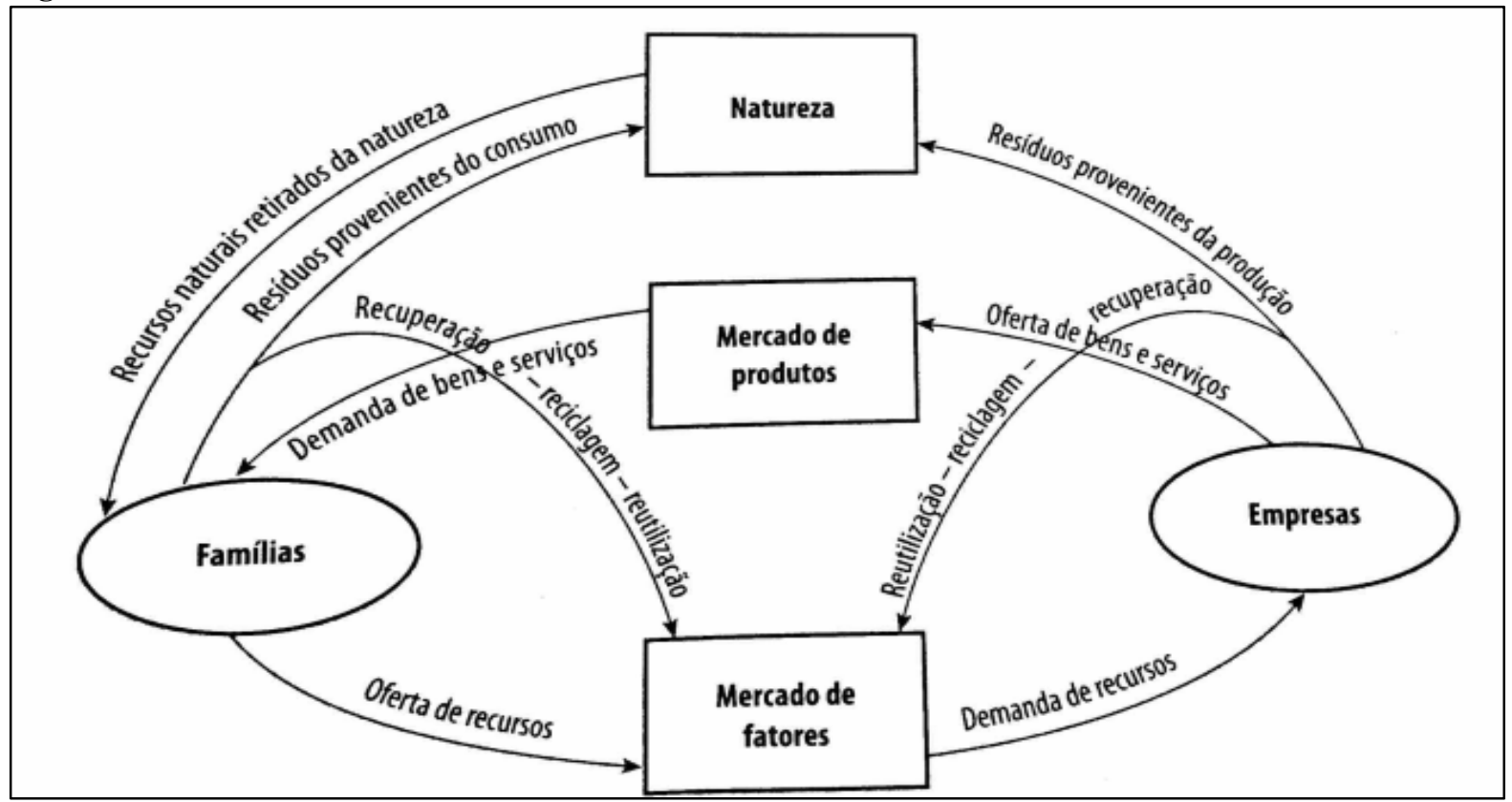

Fonte: extraído de (THOMAS e CALLAN, 2012, p. 507).

O processo da economia ambiental, porém, vai além da relação com a natureza. No contexto empresarial se define a sustentabilidade a partir de três pilares (Triple Bottom Line), sobretudo, pós anos de 1990: 1) econômico; 2) social; e 3) ambiental. Porém, Sachs (1993) apresenta a discussão sobre o desenvolvimento sustentável a partir de diferentes dimensões, além da ecologia - muito disseminada e entendida como sustentabilidade. Para o autor, as dimensões de análise da sustentabilidade, são: 1) social (equidade na distribuição de bens e renda); 2) econômica (alocação e gerenciamento eficiente de recursos); 3) ecológica (conjunto de medidas); 4) espacial (melhor distribuição territorial dos assentamentos humanos e das atividades econômicas); e 5) cultural (mudanças culturais com caráter endógeno). Sendo assim, o desenvolvimento sustentável, de fato, somente pode (rá) ocorrer quando as diferentes dimensões forem atendidas (e entendidas). Uma organização somente será sustentável quando, a priori, compreender as diferentes dimensões e trabalhar com (e para) as mesmas.

Autores com publicações mais recentes já encaram em suas pesquisas o escopo de análise em diferentes dimensões. A exemplo, Morioka et at. (2018, p. 294), descrevem a sustentabilidade (e correlacionada com a gestão empresarial) como:

\footnotetext{
A integração de múltiplas dimensões, ou seja, é preciso promover a inclusão de aspectos sociais e ambientais aos "tradicionais" objetivos econômicos, a integração dos interesses de stakeholders externos aos interesses internos e individuais e a conciliação de objetivos de longo prazo no processo de tomada de decisão usualmente direcionado por motivações de decisões de curto prazo.
}

Como já demonstrado, o conceito de desenvolvimento sustentável se popularizou no mundo após os anos de 1970, quando fíca evidente que a economia não poderá crescer indefinidamente já que a base da natureza é um fator restritivo. A escala da atividade econômica terá de ser repensada no intuito de não se explorar os recursos naturais acima de sua capacidade de regeneração, nem emitir resíduos acima de sua capacidade de assimilação, e isto implica pensar, inclusive, em inovação. "O conceito de desenvolvimento sustentável surge justamente como elo entre a economia (num sentido amplo, envolvendo também a dimensão social) e a ecologia, promovendo a reaproximação entre estes dois campos do saber" (BURSZTYN e BURSZTYN, 2012, p. 47). Neste sentido, em 2010 é aprovada a Lei

R. Eletr. do Alto Vale do Itajaí - REAVI, v. 7, n. 11, p. 01-09, dez., 2018 ISSN: 2316-4190, DOI: $10.5965 / 2316419007112018103$ 
denominada de Política Nacional de Resíduos Sólidos (PNRS) - Lei 12.305/2010 - que institui, dentre outros instrumentos, a logística reversa como importante processo de redução de resíduos (re) emitidos.

Júnior et al. (2011) descreveram que, no contexto para a exequibilidade da sustentabilidade empresarial, há uma relação entre causa (s), evento (s) e efeito (s). Analisam ainda, sob a ótica das externalidades e das nomenclaturas de eficiência, eficácia e efetividade. Neste sentido, a exequibilidade, é "algo que pode ser executado ou cumprido, exprimindo que pode ser percorrido, sem obstáculos; denota um caráter de possibilidade e, assim, traduz-se numa dimensão temporal, não se atendo apenas ao momento atual" (JÚNIOR, et al., 2011, p. 78). Assim, no contexto organizacional, a exequibilidade (em uma visão transdisciplinar) pode potencializar a construção de indicadores, uma tarefa, igualmente, difícil e necessária, como apontaram Sehnem; Lukas e Marques (2015), sobretudo, para pequenas e médias empresas. No contexto das grandes empresas (com capital aberto e com ações negociadas em Bolsa de Valores - BM\&FBovespa), fica claro que organizações que fazem parte do chamado Índice de Sustentabilidade Empresarial (ISE) - que por sua vez, adotam práticas sustentáveis e mensuradas por indicadores - possuem ações com maior valorização. Vide (BM\&FBovespa, 2018).

A partir de análises bibliométricas sobre sistemas de mensuração de desempenho e sustentabilidade (SMDS), Morioka et al. (2018, p. 294), apontam que "o número de publicações sobre SMDS tem crescido nos últimos anos, mas esse corpo de conhecimento ainda continua disperso em diferentes campos, com ligações fracas entre as diferentes "tribos" de pesquisa". Corroborando com estes dados, Feil e Schreiber (2017), descrevem que não existe um único modelo para a elaboração de índice de sustentabilidade. Diferentes processos podem ser utilizados, variando inclusive, de acordo com as informações que estão disponíveis. Assim, os autores recomendam cautela quando da mensuração e utilização de índices.

Ainda, é recorrente encontrar a relação entre sustentabilidade, empreendedorismo e inovação, esta última, muito enaltecida atualmente e vista por muitos como "a solução" aos problemas. "As demandas e mudanças do ambiente exigem adaptação das organizações tanto por meio do Empreendedor, quanto por meio da inovação" (MIGUEZ; LEZANA, 2018, p. 113). Porém, nem todo processo inovativo é, por si só, sustentável, ainda mais se analisado sob o prisma de diferentes dimensões.

A partir deste panorama, se destaca que a ação primeira para que o desenvolvimento sustentável deixe de ser apenas uma utopia, reside na sensibilização e na observação das diferentes dimensões, sobretudo, com destaque nas pessoas, no agir coletivo e no individual (MUNK, 2013). Neste interim, surge a problemática para esta pesquisa: será que os gestores de organizações empresariais da região do Alto Vale do Itajaí (Santa Catarina) compreendem as diferentes dimensões de sustentabilidade?

\section{Metodologia}

Objetivando responder a problemática apresentada, o presente texto está pautado em uma pesquisa qualitativa, bibliográfica e exploratória. Para a coleta dos dados foi utilizado o método de coleta entrevistas (semiestruturadas). A amostra foi selecionada (aleatoriamente) tendo em vista diferentes ramos de atuação na região do Alto Vale do Itajaí (Santa Catarina). Como forma de análise das respostas dadas pelos gestores, se utilizou da técnica de análise de conteúdo. O período da realização da pesquisa se deu no primeiro semestre do ano de dois mil e dezessete. Os dados pessoais dos gestores (nome e sobrenome) foram substituídos nas análises por "ID".

No total, foram entrevistados 11 (onze) gestores (ID) de diferentes organizações / empresas de pequeno, médio e grande porte. (Tabela 1)

R. Eletr. do Alto Vale do Itajaí - REAVI, v. 7, n. 11, p. 01-09, dez., 2018 ISSN: 2316-4190, DOI: $10.5965 / 2316419007112018103$ 
Tabela 1 - perfil das empresas.

\begin{tabular}{r|ccc}
\multicolumn{1}{c}{$\begin{array}{c}\text { Ramo de } \\
\text { Atividade }\end{array}$} & $\begin{array}{c}\text { Tempo de } \\
\text { Constituição } \\
\text { (em anos) }\end{array}$ & $\begin{array}{c}\text { Quantidade de } \\
\text { Funcionários }\end{array}$ & $\begin{array}{c}\text { Quantidade de } \\
\text { Turnos }\end{array}$ \\
$\begin{array}{r}\text { Confecção } \\
\text { Flexografia }\end{array}$ & 7 & 24 & 1 \\
Combustiveis & 9 & 19 & 1 \\
Pneumáticos & 18 & 8 & 1 \\
Serviços (Desenvolvimento de & 19 & 13 & 2 \\
Software) & 14 & 10 & 1 \\
Hospitalar & 22 & 563 & 3 \\
Agropecuária & 45 & 800 & 2 \\
Metalurgia & 17 & 82 & 1 \\
Material Elétrico e Iluminação & 58 & 9 & 2 \\
Alimentos & 51 & 150 & 1 \\
Saneantes Domissanitários e & 29 & 23 & \\
Imunizantes para Madeira & & & 1 \\
\hline
\end{tabular}

Fonte: dados da pesquisa.

Quanto as funções desempenhadas pelos colaboradores junto das organizações, foram selecionados aqueles gestores ("ID") que pudessem dar maiores detalhes sobre os processos organizacionais, bem como, aqueles responsáveis (ou que contribuem) pela tomada de decisão. Os dados foram tabulados, analisados e representados em quadros e tabelas a partir do uso do Software Microsoft Excel.

\section{Análise dos dados: algumas reflexões}

A amostra de gestores selecionados possui como característica geral de que $45 \%$ deles possuem graduação completa, 27\% Pós-Graduação (especialização), 18\% Ensino Médio e 10\% graduação incompleta. (Quadro 1)

Quadro 1 - perfil dos gestores entrevistados.

\begin{tabular}{|c|c|c|c|c|}
\hline ID & $\begin{array}{c}\text { Ramo de } \\
\text { Atividade }\end{array}$ & Função & $\begin{array}{c}\text { Tempo na } \\
\text { Empresa } \\
\text { (em anos) }\end{array}$ & Grau de Instrução \\
\hline 01 & Confecção & Administrador & 7 & Superior completo \\
\hline 02 & Flexografia & Diretor Industrial & 9 & Superior incompleto \\
\hline 03 & Combustíveis & Sócio Proprietário & 15 & Pós-Graduação (esp.) \\
\hline 04 & Pneumáticos & Sócio Proprietário & 17 & Ensino Médio completo \\
\hline 05 & $\begin{array}{c}\text { Serviços (Desenvolvimento } \\
\text { de Software) }\end{array}$ & Sócio Proprietário & 12 & Superior completo \\
\hline 06 & Hospitalar & $\begin{array}{c}\text { Gerente de Recursos } \\
\text { Humanos }\end{array}$ & 13 & Superior completo \\
\hline 07 & Agropecuária & Presidente & 23 & Ensino Médio completo \\
\hline 08 & Metalurgia & Diretor Executivo & 5 & Pós-Graduação (esp.) \\
\hline 09 & $\begin{array}{c}\text { Material Elétrico e } \\
\text { Iluminação }\end{array}$ & Gerente Financeiro & 19 & Superior completo \\
\hline 10 & Alimentos & Diretor Industrial & 36 & Superior completo \\
\hline
\end{tabular}

R. Eletr. do Alto Vale do Itajaí - REAVI, v. 7, n. 11, p. 01-09, dez., 2018 ISSN: 2316-4190, DOI: $10.5965 / 2316419007112018103$ 


\begin{tabular}{|c|c|c|c|c|}
\hline 11 & $\begin{array}{c}\text { Saneantes Domissanitários e } \\
\text { Imunizantes para Madeira }\end{array}$ & Gerente Geral & 3 & Pós-Graduação (esp.) \\
\hline
\end{tabular}

Fonte: dados da pesquisa.

Quando questionados sobre o entendimento do que é "sustentabilidade" e "sustentabilidade empresarial", fica evidente que o mais recorrente são respostas que a relacionam com ações para redução de impactos ambientais, ou seja, há uma percepção geral de que "sustentabilidade" está relacionada em maior intensidade com a dimensão ambiental / ecológica descrita por Sachs (1993). Ainda, se verificou que alguns gestores identificam a sustentabilidade a partir de um conceito muito disseminado, seu tripé: ambiental, econômico e social, porém, sem uma clara definição. (Quadro 2)

Quadro 2 - respostas às perguntas sobre o entendimento de "sustentabilidade" e "sustentabilidade empresarial".

\begin{tabular}{|c|c|c|}
\hline ID & O que é "Sustentabilidade" & O que é "Sustentabilidade Empresarial" \\
\hline 01 & $\begin{array}{l}\text { Entendo que devemos criar ações para suprir } \\
\text { nossas demandas atuais sem comprometer as } \\
\text { próximas gerações }\end{array}$ & $\begin{array}{l}\text { Trabalhar para garantir uma boa estabilidade } \\
\text { econômica, social e trabalho visando o bom andamento } \\
\text { das atividades da empresa para o futuro, sem } \\
\text { comprometer o meio ambiente }\end{array}$ \\
\hline 02 & $\begin{array}{l}\text { É a implementação na cadeia } \\
\text { produção/consumo de matérias primas, métodos } \\
\text { de produção e logística com o menor impacto } \\
\text { ambiental e a maior reutilização de reciclagem } \\
\text { possível. Sustentabilidade é olhar para a frente, } \\
\text { é desenvolver tecnologia, é gerar menos } \\
\text { descarte, é produzir mais com menos recursos }\end{array}$ & $\begin{array}{l}\text { É o compromisso de cada empresa na implementação } \\
\text { de processos sustentáveis de produção }\end{array}$ \\
\hline 03 & $\begin{array}{l}\text { Buscar soluções ou práticas alternativas de } \\
\text { produção e comercialização que minimizam os } \\
\text { impactos ambientais e, ou sociais também, } \\
\text { seguindo a responsabilidade social }\end{array}$ & $\begin{array}{l}\text { Heráclito citava: "nada é permanente, exceto a } \\
\text { mudança". Com essa frase mudar a mudança de } \\
\text { negociar, verificar as atitudes atuais das empresas e } \\
\text { comparar com o que se espera do futuro em temos } \\
\text { sustentáveis. Analisar quais impactos ambientais a } \\
\text { empresa proporciona e como agir frente a isso. Procurar } \\
\text { sempre antecipar-se a mudança de valores e preceitos } \\
\text { com atributos socioambientais }\end{array}$ \\
\hline 04 & $\begin{array}{l}\text { Preservar o meio ambiente e garantir o } \\
\text { desenvolvimento do mesmo }\end{array}$ & $\begin{array}{l}\text { Um conjunto de ações que a empresa toma sempre } \\
\text { observando e priorizando o meio ambiente e o } \\
\text { desenvolvimento do mesmo }\end{array}$ \\
\hline 05 & $\begin{array}{l}\text { Capacidade de se interagir com o meio ambiente } \\
\text { preservando-o, de forma a não comprometer os } \\
\text { recursos naturais das futuras gerações }\end{array}$ & $\begin{array}{l}\text { Empresa sustentável, que aplica os conceitos de } \\
\text { sustentabilidade nas suas ações, integrando de forma } \\
\text { eficiente questões sociais, energéticos, econômicos e } \\
\text { ambientais. Que respeite o ser humano e o meio } \\
\text { ambiente, enfim, um empreendimento ecologicamente } \\
\text { correto, economicamente viável, socialmente justo e } \\
\text { culturalmente diverso. A empresa atendendo suas } \\
\text { necessidades sem comprometer a possibilidade das } \\
\text { futuras gerações atenderem suas próprias necessidades }\end{array}$ \\
\hline 06 & $\begin{array}{l}\text { Sustentabilidade está ligada a proteção do meio } \\
\text { ambiente e o futuro das pessoas }\end{array}$ & $\begin{array}{l}\text { Empresas preocupadas e que tomam medidas para } \\
\text { neutralizar os gases, a água, o lixo poluente que emitem } \\
\text { para produzir o seu produto }\end{array}$ \\
\hline 07 & Tripé - social, econômico e ambiental & $\begin{array}{l}\text { A empresa, estando economicamente equilibrada, no } \\
\text { financeiro, no operacional e no social }\end{array}$ \\
\hline 08 & $\begin{array}{l}\text { Sustentabilidade é a capacidade pela qual temos } \\
\text { de interagir, de lidar com nosso planeta sem } \\
\text { comprometer os recursos naturais }\end{array}$ & $\begin{array}{l}\text { É a forma que a empresa encontra para produzir, } \\
\text { desenvolver sua atividade sem comprometer o meio } \\
\text { ambiente. A forma de desenvolver sua atividade } \\
\text { visando o respeito ao meio ambiente }\end{array}$ \\
\hline 09 & $\begin{array}{l}\text { Algo que possa ser mantido mediante a própria } \\
\text { produtividade, sem a necessidade de recursos } \\
\text { extras oriundos de outra fonte. Também tenho a }\end{array}$ & $\begin{array}{l}\text { A empresa tem que se manter, através de sua } \\
\text { produtividade, seu faturamento, gerando lucros e não } \\
\text { depender de injeção financeira de sócios ou outra }\end{array}$ \\
\hline
\end{tabular}

R. Eletr. do Alto Vale do Itajaí - REAVI, v. 7, n. 11, p. 01-09, dez., 2018 ISSN: 2316-4190, DOI: $10.5965 / 2316419007112018103$ 


\begin{tabular}{|l|l|l|}
\hline & $\begin{array}{l}\text { segunda percepção em relação a } \\
\text { sustentabilidade em se falando de } \\
\text { aproveitamento de desperdícios, como lixo } \\
\text { reciclável, gases etc. }\end{array}$ & $\begin{array}{l}\text { entidade financeira como bancos por exemplo. Mas, } \\
\text { poderíamos citar a questão de produção de matéria } \\
\text { prima através de materiais reciclados também, como os } \\
\text { gases, gerando energia }\end{array}$ \\
\hline $\begin{array}{l}\text { Qualidade de vida; fazer diferente do que era } \\
\text { feito no passado; pensar e agir diferente; cuidar } \\
\text { para não faltar; o empresário bem-sucedido no } \\
\text { futuro vai ser aquele que equilibra os fatores } \\
\text { ambientais, sociais e econômicos }\end{array}$ & $\begin{array}{l}\text { Produzir produtos que estejam relacionados a matéria- } \\
\text { prima comprometida a cadeia sustentável ou seja: } \\
\text { adquirir produtos conhecendo a origem; fabricar } \\
\text { conhecendo o processo e aproveitando todos os } \\
\text { recursos que promovam o menor impacto ambiental; } \\
\text { comercializar o produto que chega as mãos do } \\
\text { consumidor com segurança e confiabilidade }\end{array}$ \\
\hline 11 & $\begin{array}{l}\text { Sustentabilidade para o negócio, para a a } \\
\text { sociedade e para o meio ambiente em perfeita } \\
\text { harmonia entre elas }\end{array}$ & $\begin{array}{l}\text { A própria atividade render o suficiente para manter-se } \\
\text { através de um sistema congruente entre setores internos } \\
\text { e mercado externo }\end{array}$ \\
\hline
\end{tabular}

Fonte: dados da pesquisa.

No que versa sobre a "sustentabilidade empresarial" há uma tendência de entendimento que a relaciona com a dimensão econômica e ambiental. De forma geral, parece que ocorre aquilo que Veiga e Zatz (2008) enfatizaram, uma popularização (e até mesmo uma demagogia / falácia) do conceito de sustentabilidade, mesmo entre os gestores com graduação e pós-graduação. Assim sendo, não foi percebido uma diferença significativa nas respostas dadas entre aqueles gestores com grau de instrução diferentes. Em alguns casos, fica nítido que os gestores colocam a culpa pelo fato da empresa não "ser sustentável" em questões de caráter exógeno, como por exemplo, burocracia e até mesmo, ausência de incentivo por parte do governo.

Quando questionados sobre "quais ações sustentáveis a empresa possui", se verifica que de todas as ações listadas a mais recorrente diz respeito a coleta e separação de resíduos / reciclagem / reaproveitamento. Considerando os dados coletados, a empresa do setor pneumático informou que realiza a coleta de pneus utilizados, o que por sua vez, vai de encontro com a Política Nacional de Resíduos Sólidos (Lei 12.305/2010), em que no seu Art. 33 enfatizase que "São obrigados a estruturar e implementar sistemas de logística reversa, mediante retorno dos produtos após o uso pelo consumidor, de forma independente do serviço público de limpeza urbana e de manejo dos resíduos sólidos, os fabricantes, importadores, distribuidores e comerciantes de": III - "pneus".

Cabe destaque ao relato do gestor "ID 2" quando diz que, "vivemos no terceiro mundo, pesquisa e desenvolvimento em sustentabilidade é assunto para países e empresas estáveis e capitalizadas”. É preocupante, tendo em vista que implementar práticas sustentáveis, em diferentes dimensões, não necessariamente, estão relacionadas a tais questões (ou contexto).

Do total amostral de gestores entrevistados, 7 deles disseram estar satisfeitos com as ações sustentáveis que a empresa tem realizado, 3 disseram não estar satisfeito e 1, em parte. Considerando para análise as diferentes dimensões de sustentabilidade, se pode destacar que a maior parte das ações estão voltadas às dimensões social e ambiental. (Tabela 2)

Tabela 2 - projetos sociais, econômicos, ambientais e certificações - por quantidade informada.

\begin{tabular}{c|cccc}
\hline \multicolumn{2}{c}{ SOCIAIS } & ECONÔMICOS & AMBIENTAIS & CERTIFICAÇÕES \\
\hline ID 01 & 2 & 0 & 0 & 0 \\
ID 02 & 0 & 0 & 0 & 0 \\
ID 03 & 1 & 1 & 1 & 0 \\
ID 04 & 0 & 0 & 0 & 0 \\
ID 05 & 1 & 0 & 2 & 0 \\
ID 06 & 6 & 0 & 2 & 1
\end{tabular}

R. Eletr. do Alto Vale do Itajaí - REAVI, v. 7, n. 11, p. 01-09, dez., 2018 ISSN: 2316-4190, DOI: $10.5965 / 2316419007112018103$ 


\begin{tabular}{l|llll} 
ID 07 & 0 & 1 & 1 & 5 \\
ID 08 & 2 & 3 & 3 & 0 \\
ID 09 & 0 & 0 & 1 & 0 \\
ID 10 & 2 & 5 & 3 & 1 \\
ID 11 & 0 & 0 & 1 & 1 \\
\hline
\end{tabular}

Fonte: dados da pesquisa.

Muitos dos gestores não entendem que a dimensão econômica também faz parte da análise do desenvolvimento sustentável. Porém, não é de hoje que se discute a relação entre crescimento, desenvolvimento econômico e desenvolvimento sustentável, este último, mais recente. Em 5 empresas entrevistadas não há projetos sociais sendo executados. Em 7 não há projetos econômicos e em 7 não há certificações. Sobre projetos sociais, na maior parte dos casos que a empresa alega existir, diz respeito a contribuição a alguma instituição (donativos financeiros ou não). Com relação as certificações, a empresa do setor agropecuário é aquela em que o gestor (ID 07) informou o maior número de certificações. Este fato pode estar diretamente relacionado com as exigências legais (instrumentos de comando e controle) para o próprio setor. Outro fato interessante de se refletir diz respeito aos projetos econômicos. Quando questionados sobre o entendimento acerca de "sustentabilidade empresarial", foi recorrente a resposta na dimensão econômica, porém, na maior parte dos casos analisados, não há projetos econômicos previstos.

Quando indagados sobre "quem deve promover a sustentabilidade", entre o rol governos; iniciativa privada; cidadãos; instituições de ensino; ONG's; e outros, quase unânime elencaram "todos". Cabe destaque e reflexão sobre o que informaram alguns dos gestores:

○ “ID 02 " relatou que as ONG's não possuem papel de promover a sustentabilidade;

○ “ID 09" disse que apenas os governos e os cidadãos devem promover a sustentabilidade;

○ "ID 11" informou que apenas a iniciativa privada deve promover a sustentabilidade.

Desta forma, se verifica que ainda existe muito o que ser discutido (indispensável o pensamento crítico-reflexivo) no que tange a sustentabilidade, sobretudo, no contexto de gestão empresarial. Sehnem; Lukas e Marques (2015), após processo de análise com estudos de casos, relataram que há um certo nível de dificuldade de pequenas e médias empresas para elaborar relatórios de sustentabilidade, bem como, monitorar indicadores, tendo em vista falta de recursos humanos. "A elaboração de um relatório de sustentabilidade é um processo simples, que requer o desejo para iniciar e disciplina para monitorar os parâmetros relevantes para a organização" (SEHNEM; LUKAS e MARQUES, 2015, p. 39). Pensando neste processo e tentando apontar um caminho para que a gestão nas empresas possa refletir sobre sustentabilidade, se destaca que é primordial a integração / existência de três quesitos: 1) sensibilização; 2) discussão; e 3) planejamento. (Figura 3) 
Figura 3 - gestão à sustentabilidade.

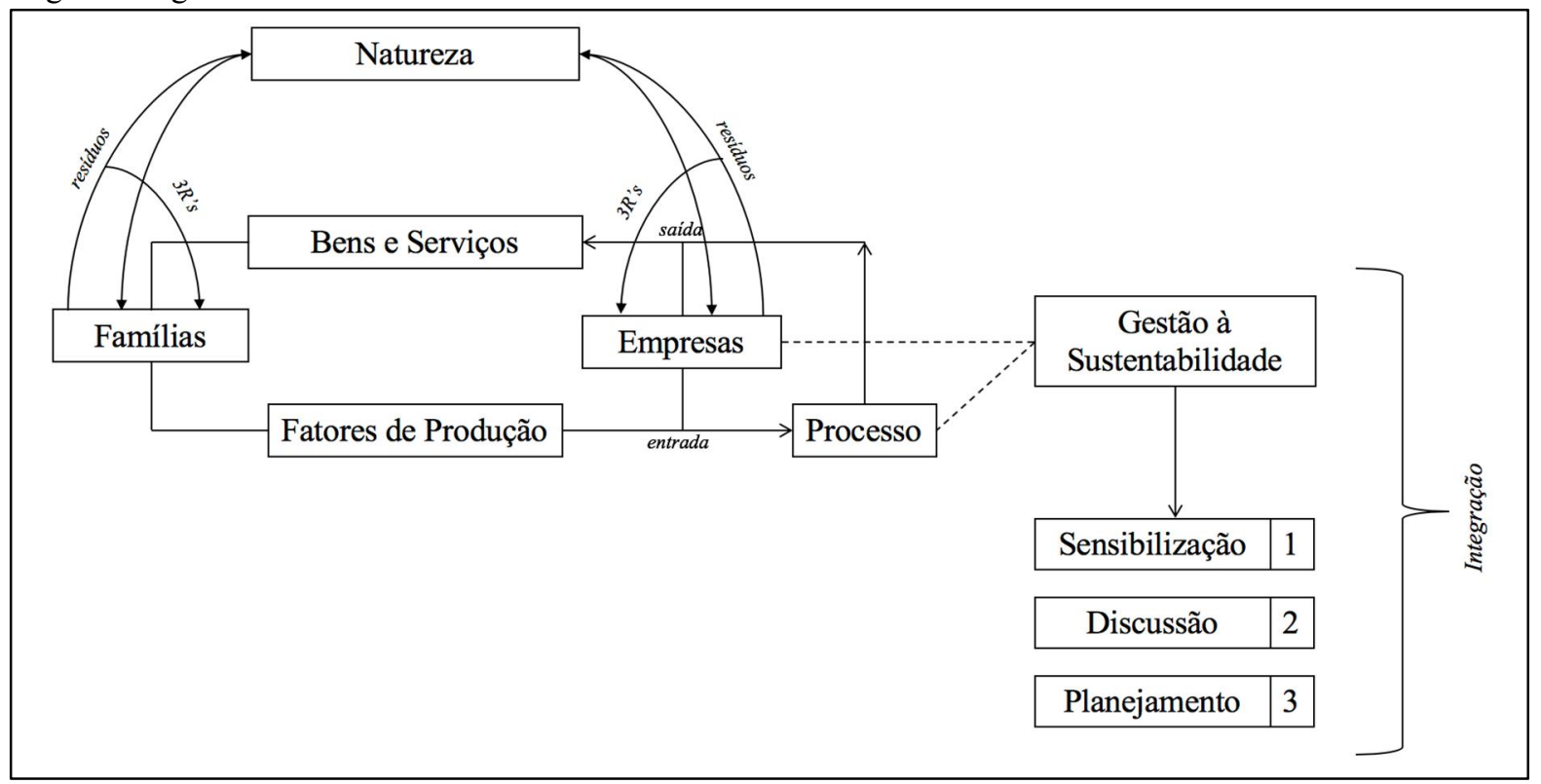

Fonte: elaborado a partir de (VASCONCELLOS, 2006), (THOMAS e CALLAN, 2012) e (BURSZTYN e BURSZTYN, 2012).

A gestão à sustentabilidade necessita na fase 1 - sensibilização - de momento para realização de ações que visem demonstrar a todos os envolvidos no (s) processo (s), desde a presidência, gestores e aos colaboradores (de todos os setores) o que realmente significa "sustentabilidade" e qual o papel e responsabilidade de cada um. É o momento de refletir sobre as diferentes dimensões e demonstrar que todos fazem parte do processo (contexto interno e externo). Trabalhos como palestras, dinâmicas interativas e atividades são importantes a esta fase. Na fase 2 - discussão - após já sensibilizados sobre o que realmente é sustentabilidade, é momento de discutir sobre as ações já existentes e quais ações podem ser desenvolvidas, mensurando potencialidades e dificuldades. Trabalhos com metodologia amparadas em condicionantes, potencialidades e deficiências (CDP) podem ser utilizadas. Já, na fase 3 planejamento - é o momento para traçar o caminho e seus planos (curto, médio e longo prazo). É preciso elaborar documento com as diretrizes, cronogramas, metas etc. (incorporando ao planejamento estratégico), definindo os mínimos detalhes. Frisa-se que a integração é fator fundamental, para tanto, um modelo de gestão participativo (colaborativo) é igualmente necessário.

\section{Considerações Finais}

Posto o aporte teórico neste estudo e a partir da análise da pesquisa realizada com gestores de diferentes empresas da região do Alto Vale do Itajaí (Santa Catarina), se verifica que a sustentabilidade ainda é entendida, sobremaneira, como "ecologia" - dimensão ambiental descrita por Sachs (1993). Historicamente, por meio das Teorias da Administração Científica, se pode perceber as diferentes formas como se encaravam os processos produtivos e as relações constituídas neste entorno, cabendo destaque para o fato de que aquelas teorias do século XIX e início do século XX pouco se preocupavam com dimensões sustentáveis.

○ No século XIX, predominava o modelo com foco na segmentação e na produção em série e subordinação funcional (centralização). O importante era produzir; 
- No século XX as relações humanas passam a figurar este cenário, não no sentido de "valorização", mas sim, as pessoas eram exploradas (suas potencialidades) à maximização da produção;

- Ainda, no século XX, a teoria da "burocracia" impera como forma de imposição de poder;

- Após segunda metade do século XX surgem as teorias com base nos sistemas, objetivos, desenvolvimento organizacional e contingencial;

- Atualmente, século XXI, se verifica no contexto organizacional uma ascensão de modelos mais participativos (em teoria, pelo menos), a chamada gestão colaborativa e governança corporativa (bem como, de modelos de gestão oriundos das chamadas Startups).

Para processo de positivo desenvolvimento, enfatizando as diferentes dimensões de sustentabilidade, modelos mais recentes (atuais) tendem a ser mais promissores, embora ainda existam muitas empresas que adotam modelos do século XIX. Assim, a reforma para a sustentabilidade organizacional / empresarial reside na reforma da gestão, que por sua vez, reside na reforma pensamento, se utilizando aqui de analogia com os pensamentos de Morin (2002; 2013). Se postula que, indiferente do porte (ou tamanho) da empresa, se faz necessário para que a sustentabilidade possa emergir em diferentes dimensões: i) sensibilização; ii) discussão e iii) planejamento.

Sendo assim, a cultura organizacional interfere no processo de reflexão crítica a respeito do desenvolvimento sustentável. Como se pode perceber, para alguns gestores da região analisada, a sustentabilidade empresarial diz respeito unicamente a dimensão econômica. O presente estudo focou na análise em uma amostra da região do Alto Vale do Itajaí (Santa Catarina) - limitação do estudo - o que por sua vez, requer estudos comparativos em demais regiões catarinenses, bem como, brasileiras - estudos futuros.

A partir do questionamento desta pesquisa, se verifica que para a gestão ao desenvolvimento sustentável (diferentes dimensões) ainda é preciso avançar. Mais importante do que falar sobre sustentabilidade (como discurso retórico), está o ato de praticar e implementar ações que de fato contribuam ao desenvolvimento sustentável, sendo este, o maior valor para o cliente e para a sociedade. Não só de grandes ações que se precisa. Pequenas atitudes, quando somadas, contribuem ao processo de desenvolvimento sustentável e para a manutenção da sociedade, pensado em diferentes dimensões, e que integradas, maximizam a sustentabilidade local, regional e global (organizacional / empresarial e pessoal).

\section{Referências}

AGENDA 21. United National Conference on Environmental and Development. Rio de Janeiro, 1992.

ARAÚJO, L. C. G. de. Organização, sistemas e métodos e as tecnologias de gestão organizacional: arquitetura organizacional, benchmarking, empowerment, gestão pela qualidade total, reengenharia: vol 1, 4 ed. São Paulo: Atlas, 2009.

BARROS, D. F.; COSTA, A. de M. da. Consumo consciente e resistência. In: CHAUVEL, M. A.; COHEN, M. (Org.) Ética, sustentabilidade e sociedade: desafios da nossa era. Rio de Janeiro: Mauad X, 2009. p. 175-192.

BECK, U. Risk society. Towards a new modernity. Londres: Sage Publications, 1992.

R. Eletr. do Alto Vale do Itajaí - REAVI, v. 7, n. 11, p. 01-09, dez., 2018 ISSN: 2316-4190, DOI: 
BRASIL. Constituição (1988). Constituição da República Federativa do Brasil. Brasília, DF: Senado Federal: Centro Gráfico, 1988. 292 p

BRASIL. Política Nacional de Educação Ambiental. Lei no 9.795 de 27 de abril de 1999.

BRASIL. Lei $\mathbf{n}^{\mathbf{0}}$ 10.257, de 10 de julho de 2001. Estatuto da Cidade e Legislação Correlata. 2. ed., atual. Brasília: Senado Federal, Subsecretaria de Edições Técnicas, 2002.

BRASIL. Lei no. 11.445, de 05 de janeiro de 2007 - Lei do Saneamento Básico.

BRASIL. Lei no . 12.305, de 02 de agosto de 2010 - Política Nacional de Resíduos Sólidos.

BARBOSA, G. S. O desafio do desenvolvimento sustentável. Revista Visões $4^{a}$ Edição, $\mathrm{N}^{\circ} 4$, Volume 1 - Jan/Jun 2008.

BM\&FBOVESPA - Índice de Sustentabilidade Empresarial (ISE). Disponível em:< http://www.bmfbovespa.com.br/pt br/produtos/indices/indices-de-sustentabilidade/indice-desustentabilidade-empresarial-ise.htm> Acesso em: jun. de 2018.

BOFF, L. Crise: Oportunidade de Crescimento. Campinas: Verus, 2002.

BOFF, L. América Latina en Movimiento: ¿Vivir mejor o "el buen vivir"? Matéria de 30/03/2009. Disponível em: <http://alainet.org/active/29839\&lang=es > Acessado em: abr. de 2018 .

BURSZTYN, M.; BURSZTYN, M. A. Fundamentos de política e gestão ambiental: os caminhos do desenvolvimento sustentável - Rio de Janeiro: Garamond, 2012.

CMMAD - Comissão Mundial sobre Meio Ambiente e Desenvolvimento. Nosso futuro comum. 2a ed. Tradução de Our common future. 1a ed. 1988. Rio de Janeiro: Editora da Fundação Getúlio Vargas, 1991.

COSTA, H. S. de M. Meio Ambiente e Desenvolvimento. Um convite à leitura, In HISA, Cássio Eduardo Viana (Org.) Saberes ambientais, Editora da UFMG, Belo Horizonte, 2008.

DALY, H. E. A economia ecológica e o desenvolvimento sustentável. Textos para debate n. 34, AS-PTA, Rio de Janeiro, 1991.

DAVENPORT, T. H. Reengenharia de processos: como inovar na empresa através da tecnologia da informação. 2. ed. Rio de Janeiro: Campus, 1994.

ELIAS, N. A sociedade dos indivíduos. Rio de Janeiro: Jorge Zahar Ed., 1994.

ECKSCHMIDT, A.; BESKOW, E. Sustentabilidade para todos: faça sua parte. Florianópolis: Insular, 2014.

FEIL, A. A.; SCHREIBER, D. Análise da estrutura e dos critérios na elaboração do índice de Sustentabilidade. SUSTENTABILIDADE EM DEBATE, (S.1.), v. 8, n. 2, p. 30 - 43, set. 2017. Disponível em: <http://periodicos.unb.br/index.php/sust/article/view/21516>. Acesso em: 18 jun. 2018. 
FOLADORI, G.; TOMMASINO, H. "Controversias sobre sustentabilidad", In Antônio Fernando Silveira Guerra e Mara Lucia Figueiredo (Orgs.) As sustentabilidades em diálogos. Editora da Univali, Joinvile, 2010.

FREITAS, R. De C. M.; NÉLSIS, C.M.; NUNES, L.S. A crítica marxista ao desenvolvimento (in) sustentável. In: R. Katál., Florianópolis, v. 15, n. 1, p. 41-51, jan./jun. 2012.

JÚNIOR, W. P. et al. Sustentabilidade empresarial e a dimensão da exeqüibilidade. Navus Revista de Gestão e Tecnologia, (S.1.), v. 1, n. 1, p. 67-81, sep. 2011. Disponível em: $<$ http://navus.sc.senac.br/index.php/navus/article/view/13/16>. Acesso em: 17 jul. de 2018.

KLEIN, L. L. et al. Uso de Resíduos de Pneumáticos Inservíveis na Produção de Concreto Para Blocos: uma simulação computacional. SUSTENTABILIDADE EM DEBATE, (S.1.), v. 7, n. $1, \quad$ p. $121 \quad-\quad 139$, abr. 2016. Disponível em: $<$ http://periodicos.unb.br/index.php/sust/article/view/17355>. Acesso em: 17 jun. de 2018.

RELATÓRIO LUZ. Grupo de Trabalho da Sociedade Civil para Agenda 2030. Disponível em: $<$ http://library.fes.de/pdf-files/bueros/brasilien/14577.pdf $>$. Acesso em: 05 set. De 2018.

SILVA, D. G. da. A IMPORTÂNCIA DA EDUCAÇÃO AMBIENTAL PARA A SUSTENTABILIDADE. 2012. Disponível em: <http://www.uniedu.sed.sc.gov.br/wpcontent/uploads/2014/04/DANISE-GUIMARAES-DA-SILVA.pdf> . Acesso em: 19 out. 2015.

GRINOVER, L. O planejamento físico-territorial e a dimensão ambiental. Cadernos FUNDAP. São Paulo, Ano 9, n. 16, jun./1989.

MAGNAGO, A. A. et al.. Uma proposta metodológica de análise socioeconômica para estudos ambientais e de reordenamento territorial. Rio de Janeiro: IBGE,1997.

MARTINe, G. População, Meio Ambiente e Desenvolvimento. Verdades e Contradições. Editora da Unicamp, Campinas. (Introdução à demografia na questão ecológica: falácias e dilemas reais (pp. 9-19) e Cap 1: População, meio ambiente e desenvolvimento: o cenário global e nacional (pp. 21-41)), 1993.

MARX, K. O Capital - Crítica da Economia Política. Livro 1: O Processo de produção do Capital. Volume II, $4^{a}$ edição. Rio de Janeiro: Bertrand Brasil, 1989.

MATIAS-PEREIRA, José. Manual gestão pública contemporânea. São Paulo: Atlas, 2008.

MIGUEZ, V. B.; LEZANA, Á. G. R. Empreendedorismo e inovação: a evolução dos fatores que influenciam o empreendedorismo corporativo. Navus - Revista de Gestão e Tecnologia, (S.1.), v. 8, n. 2, p. 112-132, apr. 2018. Disponível em: $<$ http://navus.sc.senac.br/index.php/navus/article/view/624>. Acesso em: 07 sep. 2018.

MINTZBERG, H. Criando organizações eficázes: estruturas em cinco configurações. Tradução Ciro Bernardes - São Paulo: Atlas, 1995a.

MINTZBERG, H. The Strategy process: concepts, contexts, cases. New York: Prentice Hall, $1995 b$.

MINTZBERG, H., AHLSTRAND, B., e LAMPEL, J.. Safári de Estratégia. São Paulo: Bookman, 2000.

R. Eletr. do Alto Vale do Itajaí - REAVI, v. 7, n. 11, p. 01-09, dez., 2018 ISSN: 2316-4190, DOI: $10.5965 / 2316419007112018103$ 
MONTEIRO. C. A. F. Geossistemas: a história de uma procura. São Paulo: Contexto, 2000.

MORIN, E. A cabeça bem-feita: repensar a reforma, reformar o pensamento. Rio de Janeiro: Bertrand Brasil, 2002.

MORIN, E. A Via para o futuro da humanidade. Rio de Janeiro: Bertrand Brasil, 2013.

MORIOKA, S. N. et al. Revisão sistemática da literatura sobre medição de desempenho de sustentabilidade corporativa: uma discussão sobre contribuições e lacunas. Gest. Prod., São Carlos, v. 25, n. 2, p. 284-303, jun. 2018. Disponível em $<$ http://www.scielo.br/scielo.php?script=sci_arttext\&pid=S0104530X2018000200284\&lng=p t\&nrm=iso $>$. Acesso em 07 set. 2018.

MUNK, L. Gestão da Sustentabilidade nas Organizações. São Paulo: Trilhas, 2013.

ORGANIZAÇÃO DAS NAÇÕES UNIDAS (ONU). Objetivos do Desenvolvimento Sustentável 2015-2013. Disponível em: $<$ https://nacoesunidas.org/pos2015/agenda2030/> Acesso em jun. de 2018.

RIBEIRO, A. de L. Teorias da Administração. São Paulo: Saraiva, 2005.

SACHS, I. Estratégias de Transição para o Século XXI, desenvolvimento e meio ambiente. São Paulo: Studio Nobel, 1993.

SACHS, I. Estratégias de transição para o século XXI. In: BURSZTYN, M. (org.). Para pensar o desenvolvimento sustentável. São Paulo: Brasiliense, 1993.

SACHS, I. Caminhos para o desenvolvimento sustentável. Rio de Janeiro: Garamond, 2000.

SAUVÉ, L.; BERRYMAN, T.; BRUNELLE, R. International proposals for environmental education: analysing a ruling discourse. In: CONFÉRENCE INTERNATIONALE SUR L'ÉDUCATION RELATIVE À L'ENVIRONNEMENT 'Environmental Education in the Context of Education for the 21st Century: Prospects and Possibilities". Actes... Larisa, Gr Actes. écia, 6-8 de outubro de 2000, p. 42-63. 2002.

SANTOS, M. Sociedade e espaço: a formação social como teoria e como método. Boletim Paulista de Geografia. n. 54. São Paulo, AGB/FFLCH-USP, 1977.

SANTOS, M. Por uma geografia nova. São Paulo: Hucitec, 1978.

SANTOS, M. Técnica, espaço, tempo - globalização e meio técnico-científico informacional. São Paulo: Hucitec, 1994.

SEHNEM, S.; LUKAS, M. C.; MARQUES, P. do D.. Elaboração e aplicação dos indicadores de sustentabilidade em pequenas e médias empresas. Navus - Revista de Gestão e Tecnologia, (S.1.), v. 5, n. 3, p. 22-41, july 2015. Disponível em: $<$ http://navus.sc.senac.br/index.php/navus/article/view/225/237>. Acesso em: 17 jun. de 2018.

SEN, A. Desenvolvimento como liberdade. São Paulo: Companhia das Letras, 2000.

SOTCHAVA, V.B. Por uma teoria de classificação de geossistemas de vida terrestre. São Paulo: IGEO/USP, 1978.

R. Eletr. do Alto Vale do Itajaí - REAVI, v. 7, n. 11, p. 01-09, dez., 2018 ISSN: 2316-4190, DOI: $10.5965 / 2316419007112018103$ 
THOMAS, J. M.; CALLAN, S. J. Economia Ambiental: aplicações, políticas e teoria. São Paulo: Cengage Learning, 2012.

VASCONCELLOS, M. A. S. de. Fundamentos de Economia. 2. ed. São Paulo, Saraiva, 2006.

VEIGA, J.E.; ZATZ, L. Desenvolvimento Sustentável, que bicho é esse? Campina, SP: Autores Associados, 2008.

WEBER, M. Essays in Sociology. Tradução por LTC-Livros Técnicos e Científicos Editora S.A. Rio de Janeiro. 1982. 